\title{
A Performance Analysis System for MEMS using Automated Imaging Methods
}

\author{
Glenn F. LaVigne and Sam L. Miller CONF-98/0/4- \\ Sandia National Laboratories, P.O. Box 5800, M/S 1080, Albuquerque, NM 87185-1080 \\ Email : glavig@sandia.gov \\ http://www.mdl.sandia.gov/Micromachine
}

\begin{abstract}
The ability to make in-situ performance measurements of MEMS operating at high speeds has been demonstrated using a new image analysis system. Significant improvements in performance and reliability have directly resulted from the use of this system.
\end{abstract}

\section{Introduction}

The recent past has seen the introduction of the first wave of commercially viable MEMS (MicoElectricalMechanical Systems), such as Analog Device's ADX50 accelerometer and Texas Instrument's Digital Light Mirror. As MEMS move from the lab to the market, the need for a standardized test infrastructure becomes more and more pressing. The semiconductor industry has a large set of tools that implement well-defined elec-

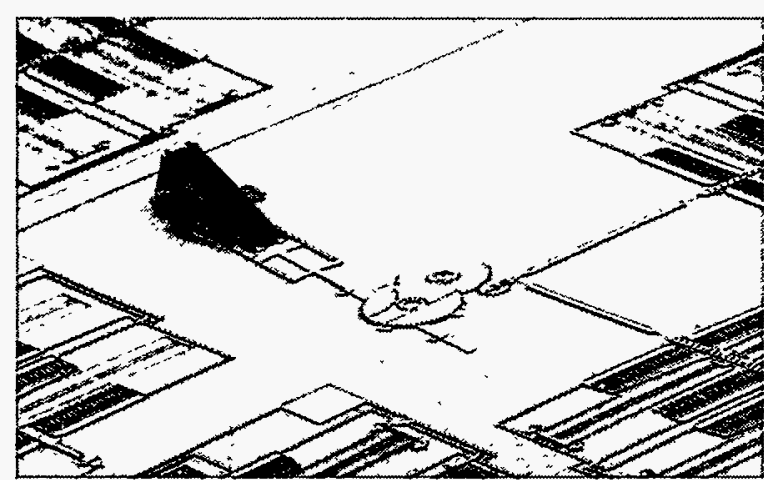

(a) trical protocols to quantify the reliability and functionality of integrated circuits. As MEMS become more important commercially, an equivalent set of tools for quantifying not only the electrical behavior but also the mechanical behavior of these devices will be required. MEMS, by their nature, present unique challenges such as quantifying the performance of mechanical devices only microns in size that may operate at speeds in excess of a hundred thousand revolutions per second. Micromechanical functional and reliability test capabilities that address such issues must be developed as new MEMS applications begin to flood the marketplace.

From the simple electrostatic resonator, each succeeding generation of MEMS devices has become increasingly complex in mechanical operation, as illustrated by the positionable mirror and safetyinterlock (Fig. 1) developed at Sandia. While the functionality of these devices has been demon-

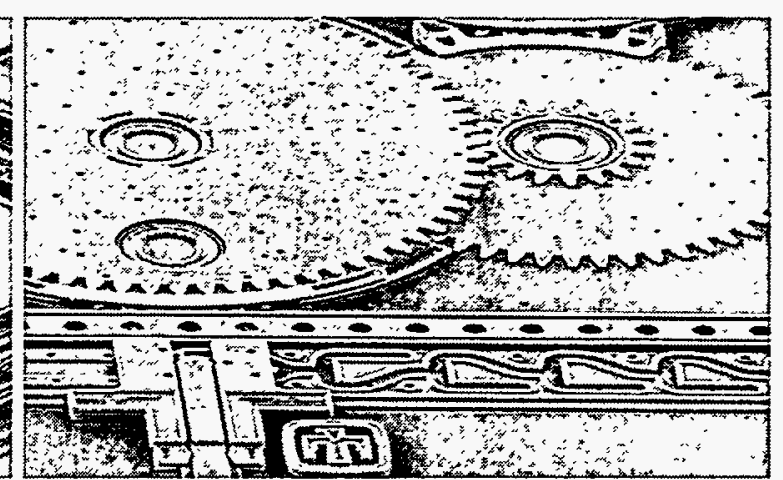

(b)

Figure 1: Two devices manufactured at Sandia that illustrate the growing mechanical and electrical complexity of MEMS. (a) A microengine drives a torque converter to actuate a mirror out of plane. (b) A close up of the descrimination section of a microsafety-interlock. 


\section{DISCLAIMER}

This report was prepared as an account of work sponsored by an agency of the United States Government. Neither the United States Government nor any agency thereof, nor any of their employees, makes any warranty, express or implied, or assumes any legal liability or responsibility for the accuracy, completeness, or usefulness of any information, apparatus, product, or process disclosed, or represents that its use would not infringe privately owned rights. Reference herein to any specific commercial product, process, or service by trade name, trademark, manufacturer, or otherwise does not necessarily constitute or imply its endorsement, recommendation, or favoring by the United States Government or any agency thereof. The views and opinions of authors expressed herein do not necessarily state or reflect those of the United States Government or any agency thereof. 


\section{DISCLAIMER}

Portions of this document may be illegible in electronic image products. Images are produced from the best available original document. 
strated, to use such a device in a commercial application requires a quantitative understanding of the performance characteristics of the device operating under a variety of conditions. With such information, the designer can optimize the performance of a MEMS microsystem to suit the application; be it a need for constant angular speed, time-dependent positioning, minimizing friction, or a combination of these and other performance issues.

In pursuit of this goal, we developed a dynamical characterization system based on the capture and analysis of video images. Like other video characterization systems for micromechanical systems (see for example [1]), the Performance Analysis System uses stroboscopic illumination to facilitate the collection of time-dependant position measurements. In contrast with [1], the Performance Analysis System, instead of tracking all device features, quickly tracks key device topological features with a high degree of accuracy under varying illumination conditions and in the presence of background interferences, such as motion drift in the test setup.

\section{Methodology}

The basic operational flow of the Performance Analysis System is outlined in Fig. 2. The system consists of a central computer that controls a strobe light source, video camera, waveform generators and digital timer circuitry. The computer system creates the drive signals to run the MEMS device under test which are then downloaded to the waveform generators. The control computer also generates a trigger marker at the start of each cycle of the drive signals. This trigger is fed into the timer circuitry which performs a divide by $\mathrm{N}$ function to step down the possibly multiple $\mathrm{kHz}$ signal to the operational range of the strobe light. Also in the timer circuitry, the divided trigger signal is time delayed by an amount dictated by the control computer. This pulse triggers both the strobe and the acquisition of a video image. By adjusting the phase of the strobe light relative to the start of the periodic drive signal, the position of the images as a function of time is directly determined.

A typical data acquisition cycle consists of the user setting the frequency at which the MEMS device is to operate and the desired position resolution for the data. Once started, the control computer automatically changes the delay on the trigger signal in fixed increment steps so as to acquire the number of data points desired. At each step, an image is captured and saved. Following the image capture process, automated image analysis is performed.

These video images contain a vast amount of information on the state of the MEMS device at a particular moment in its operation. The extraction of data from the images is performed by reinforceing the desired features and removing extraneous information. To this end, the images are fed through a series of image processing filters. For example, to characterize the rotational motion of a microengine it is necessary to find two unique points: one point on the rotating surface and one point on a stationary surface. For the Sandia microengine, the center hub and the gear/drive linkage provide such points. Therefore, a series of contrast enhancement and binary morphological filters are

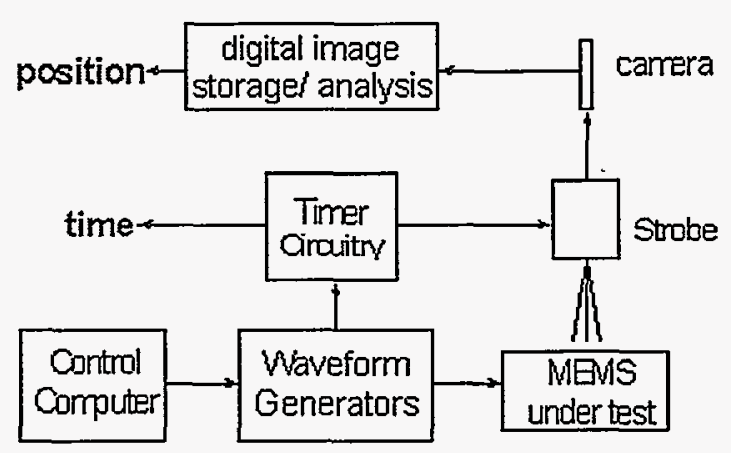

Figure 2: The block control diagram of the Performance Analysis System. 
used to accent these features and to remove unnecessary elements of the images. To illustrate this process, Fig. 3 shows the initial strobe-lit picture, an intermediate step in the image filtering and the final image used for tracking the gear/drivelinkage point. It is the final image that is compared to pre-registered patterns (templates) of the linkage point and center hub.

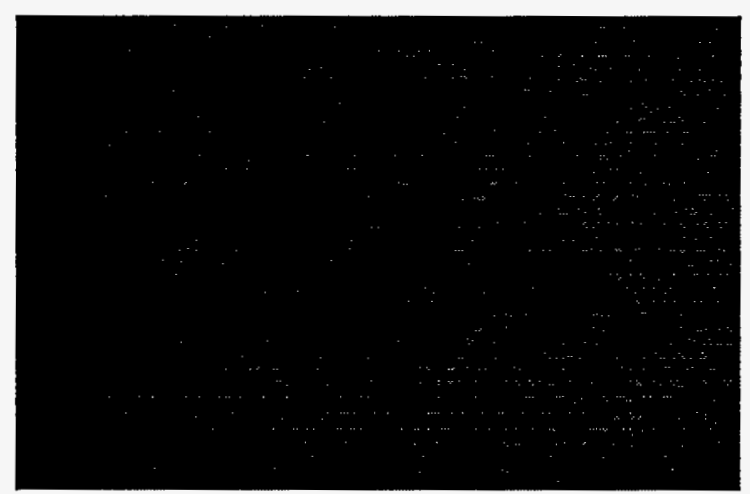

(a)

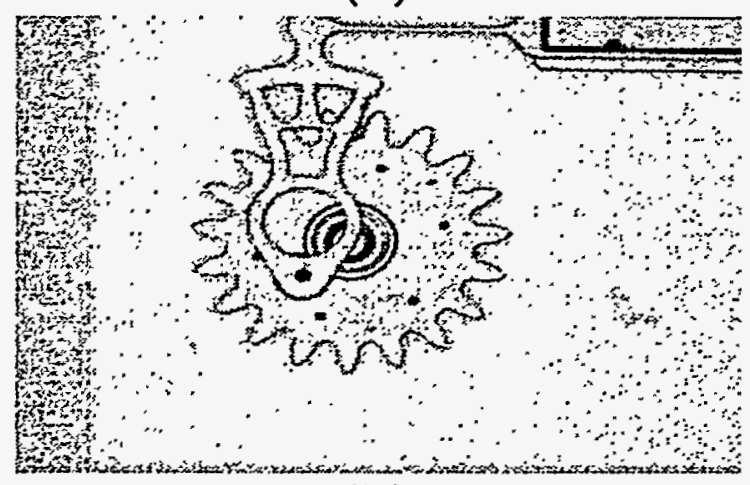

(b)
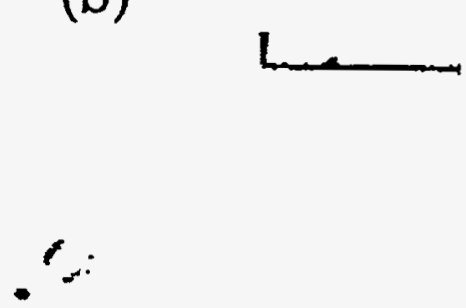

(c)

Figure 3: (a) An image of a gear captured under stroboscopic illumination. (b) Contrast enhancement and binarization filters have compensated for non-uniform illumination and have accented the physical features of the gear. (c) The image input to the template search. Notice almost all information except for pixel clusters of the center hub and linkage point has been filtered out.

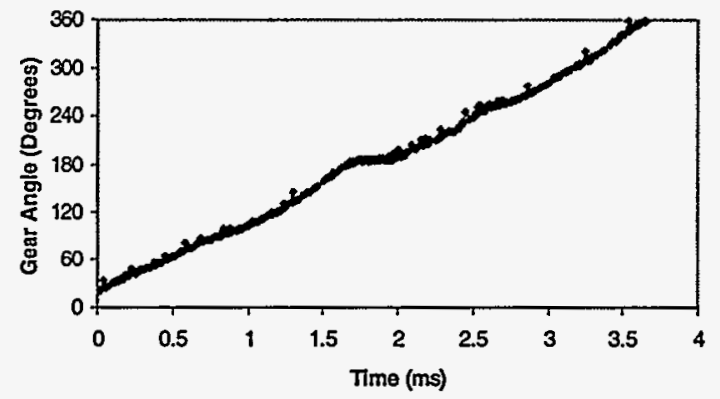

Figure 4: Data curve of rotating microengine. The fine structure visible in the data illustrates the high resolution measurements that are possible with this system.

Once filtered, the image series is fed into a template search algorithm. This algorithm looks for the template sub-image in each of the data images and reports back the X-Y position where the template was found, as well as a figure of merit for pattern match. Finally, additional analysis algorithms convert the $X-Y$ coordinates of the center and rotational points reported by the search algorithm to an angular position vs. time data set.

\section{Advantages}

The foremost advantage of the Performance Analysis System is that it is completely automated. For example, the entire data set of several hundred points shown in Fig. 4 was the result of a single data acquisition cycle. Coupled with this automation is a high degree of precision, as even the fine structure of the gear's motion can be detected and analyzed (again see Fig 4.). Also, being an imagebased system means information about the operation of all components that comprise the MEMS under test is available. This allows characterization of such complex devices as the mirror assembly.

The automated imaging system brings together a number of other useful features. The system can acquire data at a rapid rate, being limited only by the speed at which the images can be strobed, 
acquired and saved (approximately 30 frames/second using an NTSC video source). The system's spatial accuracy is governed by the optics and pixel resolution of the image capture system. Using standard optics with a resultant magnification of $1000 \mathrm{x}$ and an NTSC video source, an angular resolution of less than 1 degree on a rotational device with a radius of $17 \mu \mathrm{m}$ has been demonstrated. The time resolution of the data is governed by the operational limits of the strobe source. These features result in a system that can acquire statitiscally significant amounts of highly accurate data in an automated mode of operation.

Since the Performance Analysis System is an insitu system, it can be used to study how different operational parameters such as loading conditions, applied drive signals, and physical environments impact the behavior of a MEMS microsystem during operation. These results can be used not only to optimize the conditions under which MEMS are operated, but also to provide feedback for the optimization of both MEMS design and processing. Finally, these kinds of results directly facilitate reliability characterization and screening techniques.

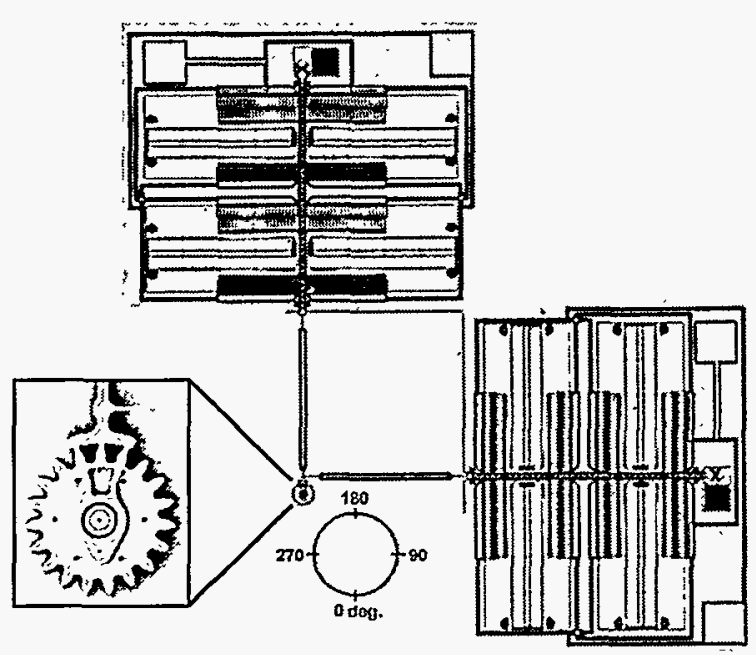

Figure 5: The microengine consists of orthogonal comb drive actuators mechanically linked to a rotating gear. Also shown is the reference angles used by all the data sets in this paper.

\section{Case Study - Lateral Clamping}

Because of its importance as the main actuation drive for many applications, the characterization of the microengine is of prime importance for the continued development of MEMS at Sandia. Hence the microengine was the first structure to be extensively studied using the Performance Analysis System. The basic microengine consists of two orthogonal electrostatically controlled combdrives mechanically coupled via linkage arms to the output gear that rotates on a center hub [3-7] (Fig. 5).

To optimize operation of the microengine, an electromechanical model of the system was developed that minimized stress and frictional forces [8-9]. Ideally, a microengine operated using such signals should display uniform rotational speed. However, data taken with the Performance Analysis System showed a consistent deviation from this ideal over a wide range of operating speeds (see Fig. 6). The anomaly in the gear's movement, where the gear slows down and comes to a halt, occurs at a position approximately 180 degrees from its static equilibrium position. Then, after a period of rest, the gear suddenly accelerates to "catch up" to its predicted position. For the remainder of its revolution, the gear follows its ideal behavior.

The repeatable character of this operational deviation revealed by the Performance Analysis System led to a detailed examination of the operation of the comb drives around the 180 degree point in the microengine's motion. The moveable comb fingers of the electrostatic drives need to remain precisely centered between the fixed comb fingers for the lateral forces to cancel. It was discovered that the voltage necessary to rotate the engine 180 degrees from rest position, coupled with the moment force being transmitted up the linkage-arm assembly, was enough to displace the comb finger assembly 


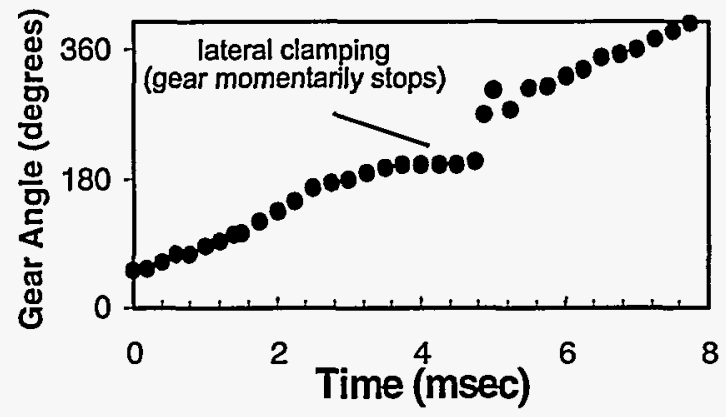

Figure 6: This data set clearly illustrates the effects of lateral clamping. At $~-180$ degrees, the gear comes to a momentary rest before snapping free and resuming its motion.

slightly to one side. This displacement produced a cascading instability that resulted in the comb drive fingers becoming laterally clamped [10] (Fig. 7).

Once the failure mechanism had been identified, the MEMS designers at Sandia implemented a number of design improvements to correct this behavior, such as lateral travel clamps and wider comb tooth spacing. Analyzing the operation of the improved microengine design using the Performance Analysis System showed the absence of the lateral clamping effect (Fig. 8).

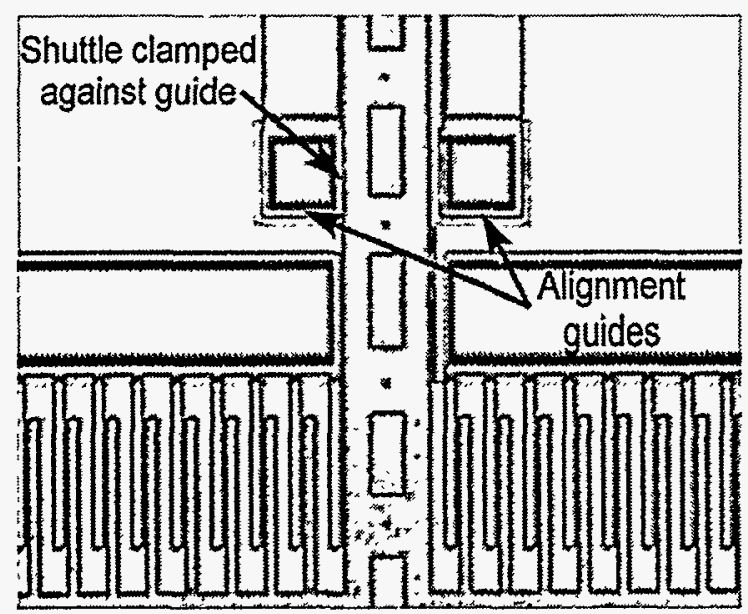

Figure 7: This picture illustrates comb drive experiencing lateral clamping. An electromechanical instability results in the movement shuttle clamping against the alignment guides, resulting in a cessation of motion revealed by the Peformance Analysis System (see Fig. 6).

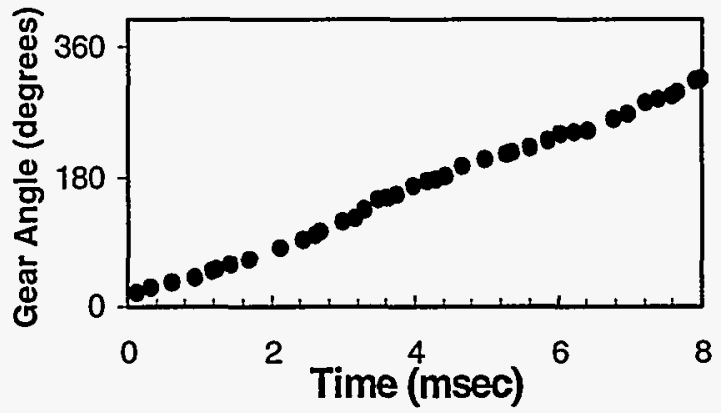

Figure 8: Data of the operation of a next generation microengine design. The lateral clamping plateau has been completely eliminated.

\section{Conclusion}

While this paper presented the use of the Performance Analysis system to characterize the operation of high-speed rotational devices, the system can just as easily be used for the study of linear, low-speed and/or non-periodic device operation. In addition, work is currently in progress to integrate the Performance Analysis System for seemless operating with the MEMS control system This will enable the operation of MEMS devices in a closed-loop control mode allowing real-time study of dynamical force effects, such as friction, and how these forces impact device operation under a multitude of operational parameters such as temperature, humidity, load conditions, lubricants and accrued operational cycles. In addition, since the existence of unknown or varying forces makes open loop operation of microsystems problematic, a closed loop system should allow more precise, reliable operation of MEMS devices.

In MEMS technology, new devices and capabilities present a vast uncharted territory in the field of characterization and reliability. With the Performance Analysis System, we have developed a powerful tool to analyze the behavior of MEMS devices. This in-situ measurement technique permits the determination of how different operational parameters affect the operational characteristics of MEMS systems. As a practical example of this, the 
Performance Analysis System has demonstrated its usefulness not only by identifying non-optimized behavior in the Sandia microengine, but also by providing the information that led to the identification and elimination of this behavior. The ultimate benefit of the Performance Analysis system was a significant improvement in both the operational stability and reliability of the devices.

\section{Acknowledgements}

The authors are grateful to Michael Callahan and Kent Meeks for the funding of this work, and the personnel of the Microelectronics Development Laboratory at Sandia National Laboratories for fabricating the devices used in this study.

Sandia is a multiprogram laboratory operated by Sandia Corporation, a Lockheed Martin Company, for the United States Department of Energy under Contract DE-AC04-94AL85000.

\section{References}

[1] D. M. Freeman and C. Q. Davis, "Using Video Microscopy to Characterize Micromechanics of Biological and Man-made Micromachines", Technical Digest of the 1996 Solid-State Sensor and Actuator Workshop, Hilton Head Isl., SC, June 3-6, pp. 161-167.

[2] William C. Tang, Tu-Cuong $\mathrm{H}$. Nguyen, Michael W. Judy and Roger T. Howe, "Electrostatic-comb Drive of Lateral Polysilicon Resonators", Sensors and Actuators A, Vol. 21, 1990, pp. 328-331.

[3] J. J. Sniegowski and E. J. Garcia, "SurfaceMicromachined Gear Trains Driven by an OnChip Electrostatic Microengine", IEEE Electron Device Lett., vol 17, pp. 366-368, 1996.

[4] J. J. Sniegowski, S. L. Miller, G. LaVigne, M. S. Rodgers, and P. J. McWhorter, "Monolithic
Geared-Mechanisms Driven by a Polysilicon Surface-Micromachined On-chip Electrostatic Engine", Technical Digest of the 1996 Solid State Sensor and Actuator Workshop, Hilton Head Island, SC, June 3-6, 1996, pp. 178-182.

[5] J.J. Sniegowski and E. J. Garcia, "Microfabricated actuators and their application to optics", Proc. SPIE Miniaturized Systems with Micro-Optics and Micromechanics, Vol. 2383, San Jose, CA, Feb. 7-9, 1995, pp. 46-64.

[6] Technology of the Year award, Industry Week, A Penton Publication, Vol 244, No. 23, Dec 18, 1995, pp. 30-34.

[7] E. J. Garcia and J. J. Sniegowski," Surface micromachined microengine", Sensors and Actuators A, Vol. 48, (1995) pp. 203-214.

[8] S. L. Miller, J. J. Sniegowski, G. LaVigne, and P. J. McWhorter, "Friction in Surface Micromachined Microengines", Proc. SPIE Smart Electronics and MEMS Vol. 2722, San Diego, Feb. 28-29, 1996, pp. 197-204.

[9] S. L. Miller, J. J. Sniegowski, G. LaVigne, and P. J. McWhorter, "Performance tradeoffs for a surface micromachined microengine", Proc. SPIE Micromachined Devices and Components II, Vol. 2882, Austin, October. 14-15, 1996, pp. 182-191. [10] M.S. Rodgers, J.J. Sniegowski, S.L. Miller, C.C. Baron, and P.J. McWhorter, "Advanced micromechanisms in multi-level polysilicon technology", SPIE Proc. Micromachined Devices and Components III, Vol. 3224, Austin, September 29, 1997, pp. 120-130. 